\title{
Effect of Teaching Program on Nurses' Performance About Scorpion Sting at Medical Emergency Unite
}

\author{
Ekhlas Tag Eldeen Ahmed ${ }^{1}$, Moggeda Mohamed Mehany ${ }^{2}$ \& Naglaa Ahmed Ahmed ${ }^{3}$. \\ 1. Specialist nursing, Faculty of Nursing, Assiut University, Egypt. \\ 2. Assistant Professor of Critical \& Emergency Care Nursing, Faculty of Nursing, Assiut University, Egypt. \\ 3. lecturer of Critical \& Emergency Care Nursing, Faculty of Nursing, Assiut University, Egypt.
}

\begin{abstract}
Background: scorpion stings represent an important and serious public health problem worldwide owing to their high incidence and potentially severe and often fatal clinical manifestations. Aim: Evaluate the effect of teaching program on nurse's performance about scorpion sting. Study design: Quasi experimental research design was utilized in this study. Setting: The study was conducted at Medical Emergency Unite in Assiut University. Sample all available nurses who were working at medical emergency unite. The sample size was (30) nurses. Tools: Two tools were used for data collection, Tool (1) Nurses' knowledge assessment sheet and Nurses' practices assessment tool. Method: preparatory, implementation and evaluation phases were used to implement study. Results: The total nurses' knowledge mean score improved from $(9.23 \pm 2.69)$ pre educational program to $(16.6 \pm 1.73)$ post its implementation, and total nurses' practice mean score improved from $(81.13 \pm 8)$ pre implementation of educational program to $(110.13 \pm 5.66)$ post its implementation. There was good improvement with highly significant difference $(\mathrm{p}<0.001)$ related to knowledge and practice. Conclusion: Majority of nurses had a satisfactory level of knowledge and practice toward scorpion sting after applying educational program. Recommendation: Nurses need in-service training programs and refreshing courses to improve their knowledge and practice.
\end{abstract}

\section{Keywords: Educational Program, Nurses, Performance, Practice \& Scorpion Sting.}

\section{Introduction}

Scorpion envenomation is a frequent and sometimes fatal occurrence in various parts of the world. Its severity is mainly related to the cardiorespiratory consequences. Pulmonary edema occurs in $7-32 \%$ of severe presentation and accounts for $25 \%$ of deaths attributable to scorpion envenomation. Recent studies have emphasized the hemodynamic mechanism of scorpion-envenomation-related pulmonary edema with an increase in pulmonary arterial occluded pressure as a constant finding. Experimental studies suggest that hemodynamic effects of scorpion venom follow a two-phase pattern: an initial one, characterized by hypertension and increased left ventricular (LV) contractility, followed by a second phase, in which hypotension, peripheral circulatory failure and impaired LV systolic function feature predominantly (Abroug et al., 2015).

Although the incidence of scorpion envenomation is higher in adults, the severity is significantly higher in children, in whom the case fatality rate is up to ten times higher than in adults. Older adults and children have an increased risk of adverse reactions to scorpion stings. People in certain areas of the world where access to medical care is restricted are also at greater risk (Saad et al., 2017).

In the United States, scorpions mainly live in the desert southwest, primarily Arizona, New Mexico and parts of California. Worldwide, they're found most often in Mexico, North Africa, South America, the Middle East, and India. Bark scorpions live under rocks, logs and tree bark - hence, the name. Bark scorpions are also the most common house scorpion, hiding in firewood, garbage pails, bed linen and shoes. Not only is the person more likely to encounter more-dangerous scorpions while traveling in certain parts of the world (Lourenço, 2018).

The symptoms of the sting start immediately with a few minutes after the sting and usually progress to a maximum severity within 5hours. Atthisperiodthemassive release of neurotransmitters results in sweating, nausea, and vomiting. The victims usually have the major signs, with the most common being mydriasis, nystagmus, hyper salivation, dysphagia, and restlessness (Padovese et al., 2018).

The principles of nursing management are: observation, cardiac monitoring, supportive treatment with intravenous fluids and electrolytes, and a meticulous use of cardiovascular agents: vasodilators, adrenergic antagonists, or calcium channel blockers in the hypertensive phase; and inotropic agents in the event of hypotension. Antiarrhythmic such as lidocaine, may be required. There is increasing evidence for the efficacy of specific antivenom. The advance in supportive care and antivenom efficacy has markedly improved the outcome of patients with scorpion envenomation (Alsawafi et al., 2015). 
As is the case in any patient, initiating immediate supportive care is paramount. This includes supplemental oxygen, aggressive pulmonary toilet, intravenous fluids if there is hypotension, and airway protection via endotracheal intubation if needed. (Tutak et al., 2018).

Many scorpion stings can be prevented by taking precautions such as shaking out clothing and shoes to dislodge any scorpions, wearing clothing that covers the body (for example, wearing gloves and tucking in pant legs into boots may limit exposure). Many pesticides that are commercially used outside on homes may make some scorpions sluggish and easier to kill before they can sting. In addition, pesticides may markedly reduce the food source of scorpions. Most researchers suggest that if patient see or feel a scorpion on the skin brush it off quickly instead of slapping it because the scorpion will likely sting you if the slap doesn't kill it (Tutak et al., 2018).

\section{Significance of study}

Scorpion sting needs special nursing to improve patient out come and prevent complication .In2019; In Assuit governorate, Upper Egypt, the last annual incidence, and mortality by scorpion stings are 100 patients who were admitted to Assuit University with scorpion sting and need special nursing care .(ElAsheer et al., 2019).

\section{Aim of the study}

To evaluate the effect of educational program about scorpion sting on the nurses' performance in the medical emergency unit.

\section{Research Hypotheses}

- There will be significant difference between posttest knowledge score and the pretest knowledge score following implementation of educational program.

- There will be significant difference between posttest practice score and the pretest practice score following implementation of educational program.

- A positive relation will exist between knowledge and practice score obtained by critical care nurses receiving educational program.

\section{Research Design}

A quasi experimental research design was used to evaluate the effectiveness of structured teaching program for present study.

\section{Setting}

The study was carried out at medical emergency unite in Assiut university hospital.

\section{Sample}

All available nurses who are working in above mentioned setting and who were 30 nurses.

Tools of the study

Two tools were used in this study

Tool (1): Nurses' Knowledge Assessment tool

This tool was developed by the researcher after review related literature to assess nurses' knowledge related to scorpion sting, this tool consists of two parts

\section{Part 1:- Socio-demographic data}

It was concerned with socio-demographic characteristic of the nurses such as age, sex, qualification and their attendance of related course training program about scorpion sting.

Part 2: Structure Interview Questionnaire sheet

It was conducted to assess the need for educational program and to evaluate it. It consisted of multiple choice questions and true or false questions that cover the following areas

- Define scorpion sting.

- Differentiate between types of scorpion.

- Pathophysiology of scorpion sting on different body system.

- List signs and symptoms of scorpion sting.-

- List degree of signs and symptoms (mild, moderate, sever)

- Identify main complication of scorpion sting.-

- Early emergency nursing care during first 6 hours from sting-

- Late emergency nursing care for these patients after 6 hours until discharge.

Scoring system of nurses' knowledge assessment tool

For multiple choice and true or false questions one grade for correct answer and zero for incorrect answer , for list questions, two grade for correct answer, one grade for incorrect answer and zero for not done .Total number of questions were 13 ,total number of grade were 18 , and scoring transformed to percent categorized as:

$<75 \%$ unsatisfied.

$>75 \%$ satisfied.

Tool (2): Practice Assessment tool

This to develop by the researcher after reviewing the literature used to assess nurse's practice about scorpion sting care such a nursing care for the patient during scorpion sting care by using observational check list(Oxygen therapy ,Air way, pulse, Endotracheal tube care ).

Scoring system of nurses 'practice assessment Each item was and categorized and scored into tow grade foe done correctly, one grade for done incorrectly and zero for not done total number of 
practice score was 118 , and scoring transformed to percent categorized as

$<75 \%$ unsatisfied.

$>75 \%$ satisfied.

\section{Method}

Data was collected in three phases 1. Preparatory phase

Permission to conduct the study was obtained from the hospital responsible authorities after explaining the aim and nature of the study.

The tool was developed by the researcher based on the relevant literature reviewing.

Content validity of the developed tool was tested for clarity by 7 experts in the field of the study ( 4 critical care nursing staff and 3 critical medicine staff) and the necessary modifications was done.

A pilot study

A pilot study: was carried out in order to assess the feasibility and applicability of the tools and the necessary modifications was done. The pilot study was done on $10 \%$ of nurses whom included in the study if no major modification was necessary. Reliability was measured by available test.

\section{Ethical consideration}

1. Research proposal was approved from Ethical Committee in the Faculty of Nursing.

2. There was no risk for study subject during application of the research.

3. The study followed common ethical principles in clinical research.

4. Informed consent was obtained from nurses that are willing to participate in the study, after explaining the nature and purpose of the study.

5. Nurses were assured that the data of this research will be used only for the purpose of research.

6. Confidentiality and anonymity were assured.

7. Nurses had the right to refuse to participate and or withdraw from the study without any rational any time.

Phase two :( Implementation phase)

- The process of data collection and implementation of teaching program consumed about 6 months.

- The researcher met all nurses and explained the purpose and importance of, the study hence; the approval for participation was secured from each nurse.

Construction of educational program

- The educational program was developed by the researcher based on the previous assessment of the nurses' knowledge and practice about scorpion sting.

- Teaching booklet was revised and modified based on the expertise comments. It was written in Arabic using simple language with illustration.
General objectives of the program

The overall objective of the developed educational program was improving the nurses' knowledge and practice about scorpion sting.

Specific objectives of the program

By the end of the program the nurses were able to

- Definition of scorpion.

- Differentiate between types of scorpion.

- Pathophysiology of scorpion sting on different body system.

- List signs and symptoms of scorpion sting.

- List degree of signs and symptoms (mild, moderate, sever).

- Identify main complication of scorpion sting.

- Early emergency nursing care during first 6 hours from sting.

- Late emergency nursing care for these patient after 6 hours until discharge.

_The program was implemented in nurses' room in the medical emergency unit in hospital. Nurses divided into groups according to work status.

\section{Teaching methods}

lecture, Discussion, Demonstration and Remonstration.

Teaching aids:-

Handout, poster, power point.

Implementation of the program:-

- Sessions arranged to take place when nurses working during morning shift in an attempt to maximize attendance.

- Questionnaire sheet was handed to all participant nurses to fill it before teaching program implementation to evaluate the theoretical knowledge, needs and collected by researcher. The time for the completion of the questionnaire sheet was ranged from $5-15 \mathrm{~min}$.

- The nurses were observed for their practice while they are working during their shifts before and after implementing the educational program

- The program was implemented 2 times for 3 subgroups (3-7 nurse).

- Educational sessions were implemented in addition to the preliminary one.

Preliminary session (1): In this session the researcher met the participant and explained the objectives and the content of the program, methods of evaluation of the program.

Session (2): Included: Definition scorpion sting, types of scorpion, signs and symptoms of scorpion sting.

Session (3): Included:-Degree of signs and symptoms of scorpion sting and the main complication of scorpion sting. 
Session (4): Included: Early emergency nursing care during first6 hours from sting, early emergency nursing care after 6 hours from the sting.

Group discussion was encouraged with continuous feedback to ensure understanding and achievement of the program objective.

- In the last session the researcher summarized and emphasized the important point.

- Each nurse demonstrated and re-demonstrated the steps individually and completely performed the steps.

Evaluation phase

The evaluation was done by the researcher twice by using tool $1 \& 2$ before (pretest) and immediately after (posttest) implementation of educational program. This was done to evaluate the effect of the program on gaining nurses' knowledge and practice toward scorpion sting.

\section{Statistical analysis}

- Data were coded and transformed into specially designed form so as to be suitable for computer enter process.

- Statistical analysis was performed using the software program package SPSS, version 20.

- Data of obtained result were tabulated in the form of frequency using mean $\pm \mathrm{SD}$, number and percentage.

- Using chi-square test to determine significant between variable.

- Using t-test to compare significant.

\section{Results}

Table (1): Distribution of Socio demographic data for Studied Nurses.

\begin{tabular}{|l|c|c|}
\hline & No $(\mathbf{n}=\mathbf{3 0})$ & \% \\
\hline Age group & & 53.3 \\
\hline Less than 25 year & 16 & 20.0 \\
\hline from 25- 30 year & 6 & 26.7 \\
\hline More than 30 year & 8 & 13.3 \\
\hline Gender & 4 & 86.7 \\
\hline Male & 26 & \\
\hline Female & & 13.3 \\
\hline Education & 4 & 20.0 \\
\hline Nursing diploma & 6 & 63.3 \\
\hline Nursing Healthy institute & 19 & 3.3 \\
\hline Nursing Technical institute & 1 & 30.0 \\
\hline Bachelor & & 70.0 \\
\hline Marital Status & 9 & 100.0 \\
\hline Single & 21 & 0.0 \\
\hline Married & & \\
\hline Attendance of Previous training & 30 & \\
\hline Yes & 0 & \\
\hline No & & \\
\hline
\end{tabular}

Table (2): Mean distribution between Nurses Knowledge about scorpion sting pre and post educational program.

\begin{tabular}{|l|c|c|c|c|}
\hline & Score & Pre(n=30) & Post(n=30) & P. value \\
\hline Definition of Scorpion sting & 2 & $1.13 \pm 0.43$ & $1.97 \pm 0.18$ & $<0.001^{* *}$ \\
\hline Sings \&Symptom & 4 & $1.93 \pm 1.23$ & $3.9 \pm 0.31$ & $<0.001^{* *}$ \\
\hline Complication & 1 & $0.7 \pm 0.47$ & $0.97 \pm 0.18$ & $<0.001^{* *}$ \\
\hline Environment suitable for scorpion life & 2 & $0.47 \pm 0.63$ & $1.77 \pm 0.43$ & $<0.001^{* *}$ \\
\hline Nursing Care & 7 & $4.1 \pm 1.37$ & $6.43 \pm 0.77$ & $<0.001^{* *}$ \\
\hline Prevention & 2 & $0.9 \pm 0.88$ & $1.57 \pm 0.63$ & $0.001^{* *}$ \\
\hline Knowledge Score & $\mathbf{1 8}$ & $\mathbf{9 . 2 3} \pm \mathbf{2 . 6 9}$ & $\mathbf{1 6 . 6 \pm 1 . 7 3}$ & $<0.001^{* *}$ \\
\hline
\end{tabular}

independent t-test $* *$ Significant difference at $p$. value $<0.01$ ) 


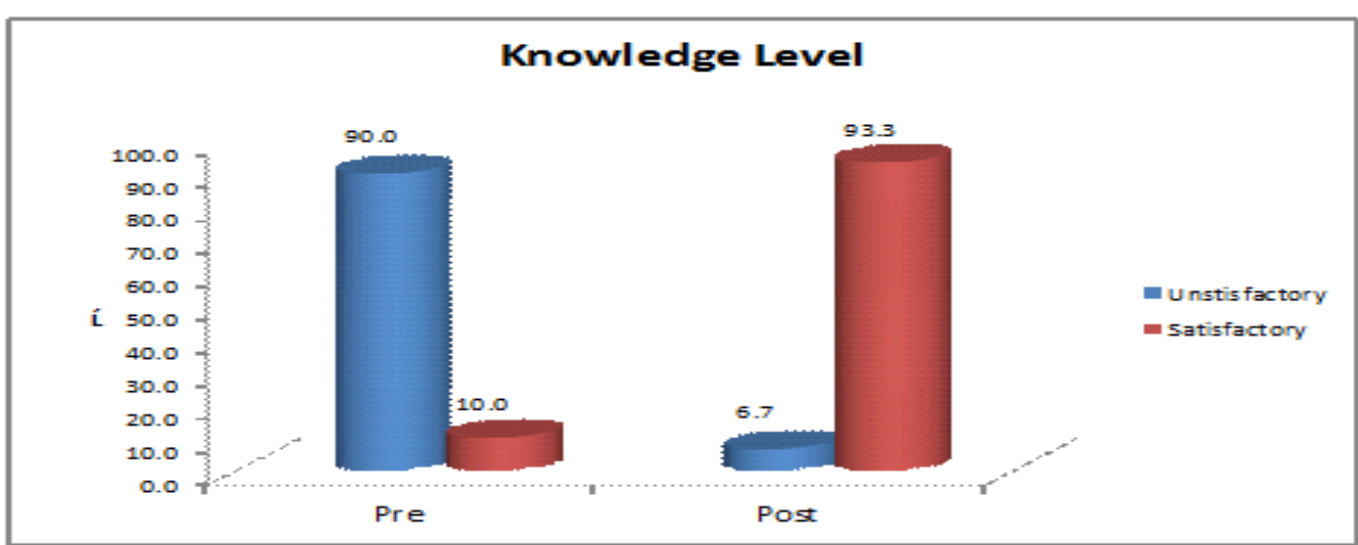

Figure (1): Percent distribution of level of nurses' knowledge score statistically.

Table (3): Relation between Nurses Knowledge and their Demographic data pre and post educational program.

\begin{tabular}{|c|c|c|c|}
\hline & \multirow{3}{*}{$\mathbf{N}$} & \multicolumn{2}{|c|}{ Knowledge Score } \\
\hline & & Pre Education & After education \\
\hline & & Mean \pm SD & Mean \pm SD \\
\hline \multicolumn{4}{|l|}{ Age group } \\
\hline Less than 25 year & 16 & $8 \pm 2.42$ & $16.63 \pm 1.82$ \\
\hline from 25- 30 year & 6 & $11.33 \pm 2.07$ & $16.33 \pm 1.97$ \\
\hline More than 30 year & 8 & $10.13 \pm 2.47$ & $16.75 \pm 1.58$ \\
\hline P. value & & $0.014 *$ & 0.909 \\
\hline \multicolumn{4}{|l|}{ education Level } \\
\hline Nursing diploma & 4 & $10.75 \pm 3.59$ & $16.5 \pm 1.73$ \\
\hline Nursing Healthy institute & 6 & $11 \pm 2.45$ & $15.83 \pm 1.94$ \\
\hline Nursing Technical institute & 19 & $8.32 \pm 2.31$ & $16.84 \pm 1.74$ \\
\hline Bachelor & 1 & $10 \pm 0$ & $17 \pm 0$ \\
\hline P. value & & 0.097 & 0.679 \\
\hline \multicolumn{4}{|l|}{ Gender } \\
\hline Male & 4 & $10.5 \pm 2.08$ & $16.5 \pm 1$ \\
\hline Female & 26 & $9.04 \pm 2.75$ & $16.62 \pm 1.83$ \\
\hline P. value & & 0.320 & 0.904 \\
\hline \multicolumn{4}{|l|}{ Marital Status } \\
\hline Single & 9 & $8.44 \pm 2.35$ & $16.78 \pm 1.2$ \\
\hline Married & 21 & $9.57 \pm 2.8$ & $16.52 \pm 1.94$ \\
\hline P. value & & 0.301 & 0.720 \\
\hline
\end{tabular}

-Independent t-test $*$ Significant difference at $p$. value $<0.05 \quad$ One Way ANOVA.

Table (4): Mean distribution between Nurses Practice About scorpion sting pre and post educational program $(\mathbf{n}=30)$.

\begin{tabular}{|l|c|c|c|c|}
\hline \multirow{2}{*}{ Max Score } & \multirow{2}{*}{} & Pre & Post & \multirow{2}{*}{ P.value } \\
\cline { 3 - 5 } & & Mean \pm SD & Mean \pm SD & \\
\hline Oxygen Therapy & 34 & $25.17 \pm 3.42$ & $31.2 \pm 2.72$ & $<0.001^{* *}$ \\
\hline Pulse & 16 & $12 \pm 2.29$ & $15.17 \pm 1.49$ & $<0.001^{* *}$ \\
\hline Air way & 42 & $24.57 \pm 5.59$ & $38.53 \pm 2.86$ & $<0.001^{* *}$ \\
\hline Endotracheal tube care & 26 & $19.4 \pm 2.37$ & $25.23 \pm 1.17$ & $<0.001^{* *}$ \\
\hline Practice Score & $\mathbf{1 1 8}$ & $\mathbf{8 1 . 1 3} \pm \mathbf{8}$ & $\mathbf{1 1 0 . 1 3} \pm \mathbf{5 . 6 6}$ & $<\mathbf{0 . 0 0 1} * *$ \\
\hline & \multicolumn{3}{|l}{} \\
\hline
\end{tabular}

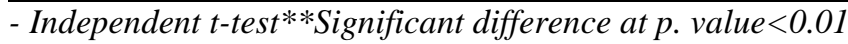




\section{Practice Level}

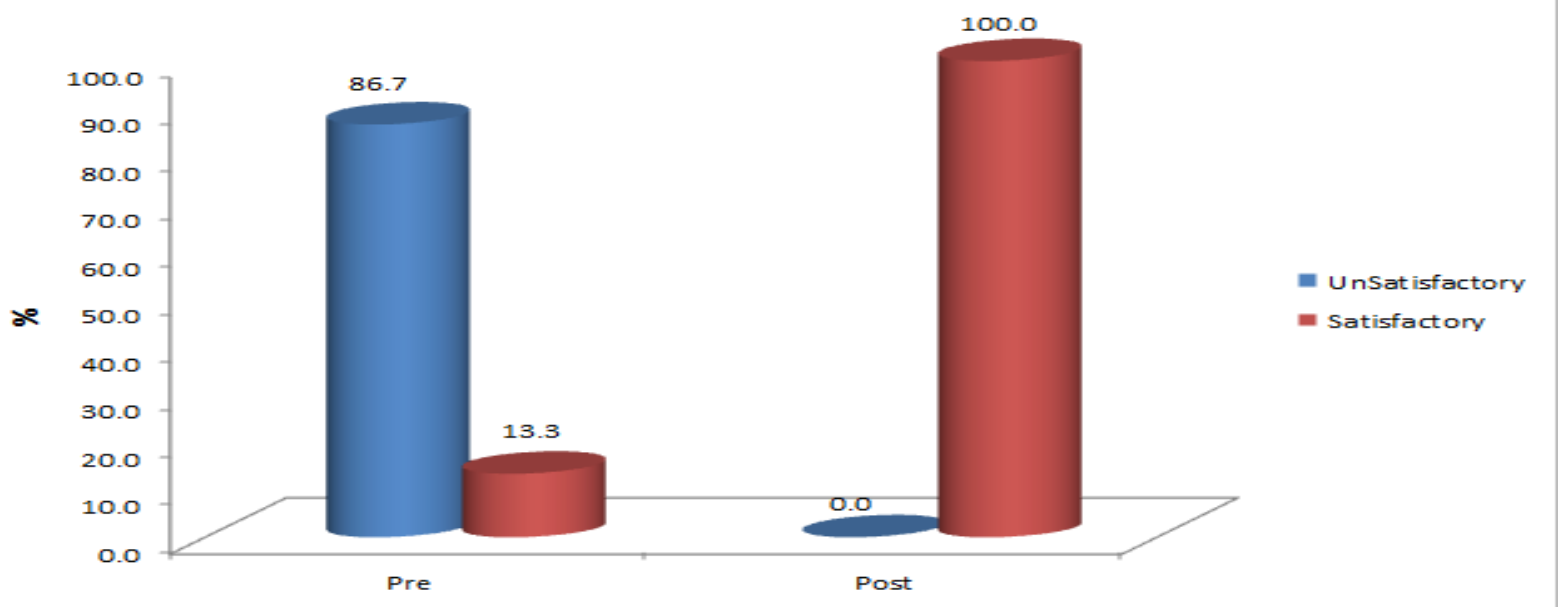

Fig (2): Percent distribution of nurses' practices score.

Table (5): Correlation between Nurses' Knowledge and their Practice pre and post educational program $(\mathbf{n}=30)$.

\begin{tabular}{|l|c|c|}
\hline \multicolumn{1}{|c|}{ Correlation } & nurses' knowledge Score \\
\hline \multicolumn{1}{|c|}{ nurses' Practice Sore } & 0.075 & $\mathrm{P}$ \\
\hline Before education & 0.392 & 0.692 \\
\hline After education & $0.032^{*}$ \\
\hline
\end{tabular}

*Statistically Significant Correlation at P. value $<0.05$.

Table (6): Relation between Nurses' Practice and their demographic data pre and post educational program.

\begin{tabular}{|l|c|c|}
\hline \multirow{2}{*}{} & \multicolumn{2}{|c|}{ Practice Score } \\
\cline { 2 - 3 } & Before education & After education \\
\cline { 2 - 3 } & Mean \pm SD & Mean \pm SD \\
\hline Age group & & $109.69 \pm 6.45$ \\
\hline Less than 25 year & $81.44 \pm 8.21$ & $111.67 \pm 5.13$ \\
\hline from 25- 30 year & $80.83 \pm 6.62$ & $109.88 \pm 4.73$ \\
\hline More than 30 year & $80.75 \pm 9.44$ & 0.770 \\
\hline P.value & 0.977 & $111 \pm 6.68$ \\
\hline Education Level & & $110 \pm 4.43$ \\
\hline Nursing diploma & $84 \pm 7.07$ & $109.63 \pm 5.97$ \\
\hline Nursing Healthy institute & $79.83 \pm 12.7$ & $117.0 \pm 0.0$ \\
\hline Nursing Technical institute & $81.32 \pm 6.69$ & 0.656 \\
\hline Bachelor & $74.0 \pm 0.0$ & $112.25 \pm 6.4$ \\
\hline P.value & 0.709 & $109.81 \pm 5.61$ \\
\hline Gender & & 0.431 \\
\hline Male & $83.25 \pm 7.8$ & $112.33 \pm 4.92$ \\
\hline Female & $80.81 \pm 8.13$ & $109.19 \pm 5.8$ \\
\hline P. value & 0.579 & 0.167 \\
\hline Marital Status & & \\
\hline Single & $79.11 \pm 8.98$ & $82 \pm 7.62$ \\
\hline Married & 0.374 & \\
\hline P.value & & \\
\hline
\end{tabular}

Independent t-test - One Way ANOVA 
Table (1): Shows that the most age of nurses was $(53.3 \%)$ and $(86.7 \%)$ of nurses were female, concerning their educational level $(63.3 \%)$ held technical institute, $(20.0 \%)$ held healthy institute of nursing.

Table (2): Shows that there was a highly significance differences in nurses knowledge mean score between pre $(9.23 \%)$ and post $(16.6 \%)$ implementation of teaching program regarding scorpion sting $(\mathrm{p}<0.01)$.

Figure (1): Illustrates that about $90 \%$ of nurses had unsatisfied knowledge pre implementation of educational program and 93.3\% of nurses had a satisfied knowledge post implementation education program with highly significance difference between them.

Table (3): Illustrates there was significant relation between total nurses' knowledge mean score and nearly all items of socio demographic data after implementation of teaching program $(\mathrm{p}<0.05)$.

Table (4): Illustrates that there was a highly significance differences in nurses practice mean scores in between pre and post implementation of teaching program as regard of scorpion sting $(\mathrm{p}<0$. 01).

Figure (2): Illustrates that about $86.7 \%$ of nurses had unsatisfied practice in pretest and $100 \%$ of nurses had a satisfied practice post implementation of educational program.

Table (5): Illustrate that there was positive correlation between knowledge and practice after implementation of education at value $<0.05$.

Table (6): Illustrate that there was no statistical significant relation between nurses' practice mean score pre and post education and there demographic statistic.

\section{Discussion}

Teaching program today is very important for the nurses to increase knowledge and practice about scorpion sting to help them to assess patient status and determine any complication which may be occur for the patient and how to treat and prevent this complication and learn the specific care for this patient and how to give this care especially during receiving treatment scorpion sting (Gharib, \& Fekry, 2017).

The present study observed that the majority of studied nurses were at the age group less than 25 years old, because Assuit university recruit recently graduated nurses to tolerate hard work of type of this unit. As regarding to sex, the majority of studied nurses was females and married. As regarding to qualification, the majority of studied nurses was technical degree. This disagree with Bower et al., (2018) who mentioned that; the administrators selected older age nurses to be able to perform mainly tasks in the emergency care unit effectively .

The result of present study was consistent with Hussein et al., (2015) who revealed that the majority of nurses working in emergency places their ages ranged from 20-40 years, married, female, and had diploma of nursing, more than half of them their experience was more than 5 year.

In my opinion the administrators should select nurses with age less than 25 years old; to tolerate hard work of emergency unit, and this help to improve patient outcome.

The presented study revealed that the total score of nurses knowledge and practice of the nurses before implementation of the educational program, was poor scores regarding total items of scorpion sting, this may be because of many factors as; not receiving $g$ previous training program about scorpion sting (deficiency in training), no updating of knowledge that received during undergraduate, no motivation from administration, no pre-employment orientation program, insufficient number of nurses, inadequate salary and lack of instructions.

The findings of the present study supported hypothesis (1), in which the mean knowledge and practice scores of the study group subjects improved significantly immediately post implementing the teaching program. Therefore, the educational program was successful in improving nurses' knowledge and practice, which could be attributed to the structure, content and process of the program.

Results of the present study were inconsistence with Tomažič et al., (2020) they reported that during pretest one third of nurses had inadequate knowledge regarding scorpion stings. After intervention showed that majority of them was gained knowledge. In this respect Ashrafi et al., (2019) mentioned that nurses must be able to expand their knowledge of this area through ongoing education, Journal, and seminars. Consequently, teaching programs for nursing staff constitute an important part. These programs are urgently designed to assess nursing staff in developing and enhancing the skills needed to provide high standards of care to their patients.

In my opinion before implementation the educational program the nurses had bad score because of many factor as; deficiency in training, no updating of knowledge that received during undergraduate, no motivation from administration ,but after implementation of the educational program the nurses score increased and improved. And this mean the educational program success because it cover all content of nursing care of scorpion sting.

The study results revealed that there was no statistical significant difference among nurses' knowledge either pre or post implementation of the teaching program 
and their socio demographic except between their ages. This was in the same line with Wright, (2015) who found that the healthcare providers, despite the precision and mastery skills, were not immune to errors due to the educational system has shortcomings or high work load and pressure as well as the responsibilities of the nurses which caused the errors so that they in need for continuous education program.

In my opinion nearly characteristics cannot affected on the level of nurse's knowledge, because of nurses need continuous education program and this according this study.

As regards to nurses' practice; The findings of the present study showed that the practice scores of the studied group subjects post implementing teaching program improved significantly. This result supported by Emmons, \& Zager, (2018) who mentioned that the level of practices significantly increased with the level of education but effects of an educational program made the correlation significant in posttest, and this attribution was due to the improvement in nursing performance which were found in present study results post teaching program this could be due to either lack of their awareness or lack of rules enforced by the hospital scorpion stings. Barton, et al., (2018) in the same line with the current study findings, their study revealed that an improvement in nurses' practice after the attendance at continuing nursing education sessions.

In my opinion after implementation of educational program the nurses' performance improved and then the practice score improved, and this mean that the educational program success and cover all item of nursing care of scorpion sting

The current study demonstrated that there was a positive correlation participants' scores of knowledge and practice .This agree with LoBiondo-Wood, \& Haber, (2017) who stated that a highly statistical significant correlation between participants' scores of knowledge and practice in pre-program and post program, 1 month and 2 months following the instructional program.

In my opinion the knowledge and practice depends on each other.

The study findings indicated that there was no statistical significant difference found between nurses' practice (pre and posttest) and their demographic characteristics either their demographic characteristics. The result of this study was not agreed with Häggman-Laitila et al., (2016) who found that, not all practices reflect knowledge and implementation of evidence-based strategies, the educational level promote evidence-based practice for patient management.
In my opinion the practice need more training and not depend on socio demographic data of nurses. And this mean the educational program cover it.

\section{Conclusion}

Based on the results of this study, it concluded that: The majority of nurses had a satisfactory knowledge and practice toward scorpion sting after applying educational program. There was statistical significant relation between total nurses' knowledge and their practice post educational program.

\section{Recommendations}

- Provide educational and training programs for critical care nurses regarding scorpion sting that can improve their knowledge and practice.

- Should be available in a written format in critical units and all units

- Regular assessment of nurses' knowledge and practices should be done with providing the nurses by nursing expertise with new evidence -base practices.

\section{References}

1. Abroug, F., Souheil, E., Ouanes, I., Dachraoui, F., Fekih-Hassen, M., \& Ouanes Besbes, L., (2015): Scorpion-related cardiomyopathy: clinical characteristics, pathophysiology, and treatment. Clinical Toxicology, 53(6), 511-518

2. Ahmed, A., Abdel-Baseer, K., Saad, K., Hassan, A., El-Houfey, A., (2015): Endocrinological and biochemical changesofscorpionism in children in Upper Egypt. Ther. Adv. Endocrinol. Metab. 6 (5), 210-216.

3. Alsawafi F., Alhinai H., Alhattali B., Awad S., Alreesi A., Alshamsi M., Demyelinating polyneuropathy following scorpion sting envenomation; a case report and review of literature. Asia Pac J Med Toxicol2015; 4(4):161164.

4. Ashrafi, N., Kuilboer, J., Joshi, C., Ran, I., \& Pande, P., (2019): Health informatics in the classroom: An empirical study to investigate higher education's response to healthcare transformation. Journal of Information Systems Education, 25(4), 5

5. Barton, G., Bruce, A., \& Schreiber, R., (2018): Teaching nurses teamwork: Integrative review of competency-based team training in nursing education. Nurse education in practice, 32, 129137

6. Bektaş, İ., \& Yardımcı, F., (2018): The effect of web-based education on the self-confidence and anxiety levels of paediatric nursing interns in the 
clinical decision-making process. Journal of Computer Assisted Learning, 34(6), 899-906.

7. Bower, R., Coad, J., Manning, J., \& Pengelly, T., (2018): A qualitative, exploratory study of nurses' decision- making when interrupted during medication administration within the Pediatric Intensive Care Unit. Intensive and Critical Care Nursing, 44, 11-17

8. EL_Asheer, O., Hammad, E., Mohamad, I., Saad, K., \& Aziz, N., (2019): Arandomized comparative between intravenous and intramuscular scorpion antivenom regimens in children .Toxicon, 159,45-49

9. Emmons, C., \& Zager, D., (2018): Increasing collaboration self-efficacy to improve educational programming for students with autism. Focus on Autism and Other Developmental Disabilities, 33(2), 120-128

10. Gharib, S., \& Fekry, N., (2017): Designing Job Descriptions for Toxicology Nurses. Asian Social Science, 13(7)

11. Gooch, M., \& Roberts, E., (2017): Changing the Emergency Department's Practice of Rapid Sequence Intubation to Reduce the Incidence of Hypoxia. Advanced emergency nursing journal, 39(4), 266-279

12. Häggman-Laitila, A., Mattila, L., \& Melender, H., (2016): Educational interventions on evidence-based nursing in clinical practice: a systematic review with qualitative analysis. Nurse education today, 43, 50-59

13. Hussein, A., Mabrouk, S., \& Abed, G., (2015): Workplace Sexual Harassment against Female Nurses and Occupational Health Outcomes. International Organisation of Scientific Research Journal of Nursing and Health Sciences, 4(3), 66-77

14. LoBiondo-Wood, G., \& Haber, J., (2017): Nursing research-E-book: methods and critical appraisal for evidence-based practice. Elsevier Health Sciences, 67-88

15. Lourenço, W., (2018): Scorpions and life-history strategies: from evolutionary dynamics toward the scorpionism problem. Journal of Venomous Animals and Toxins including Tropical Diseases, 24(1), 19.

16. Padovese, V., Dassoni, F., \& Zouboulis, C. (2018): Insect Bites, Tick Bites, and Stings 15. Pigmented Ethnic Skin and Imported Dermatoses: A Text-Atlas, 155

17. Pretorius, A., Searle, J., \& Marshall, B., (2015): Barriers and enablers to emergency department nurses' management of patients' pain. Pain Management Nursing, 16(3), 372-379

18.Saad, K., El-Hamed, M., Abo-Elela, M., Ahmed, A., Abdel-Baseer, K., AboulKhair, M.,
(2017): Neurologic complications in children with scorpionism: a retrospective study in Upper Egypt. J. Child Neurol. 32 (6), 537-542.

19. Tomažič, I., Hummel, E., Schrenk, M., Rupnik, T., \& Randler, C., (2020): Cognitive and affective outcomes of teaching about poisonous and venomous animals. Journal of Biological Education, 1-14.

20. Tutak, A., Celiker, M., Findiki, H., Karakaya, B., Tutak, A., \& Uluadag, O., (2018). Should All Scorpion Stings be Followed Up in the Intensive Care Unit?. Archives of Clinical and Biomedical Research, 2(1), 7-14

21. Wright, S., (2015): Patient safety in anesthesia: learning from the culture of high-reliability organizations. Critical Care Nursing Clinics, 27(1), 1-16 